\title{
BMJ Open Psychotropic drug use and alcohol consumption among older adults in Germany: results of the German Health Interview and Examination Survey for Adults 2008-2011
}

\author{
Yong Du, Ingrid-Katharina Wolf, Hildtraud Knopf
}

To cite: Du Y, Wolf I-K, Knopf H. Psychotropic drug use and alcohol consumption among older adults in Germany: results of the German Health Interview and Examination Survey for Adults 2008-2011. BMJ Open 2016;6:e012182. doi:10.1136/bmjopen-2016012182

- Prepublication history for this paper is available online. To view these files please visit the journal online (http://dx.doi.org/10.1136/ bmjopen-2016-012182)

Received 8 April 2016 Revised 8 August 2016 Accepted 24 August 2016

CrossMark

Department of Epidemiology and Health Monitoring, Robert Koch Institute, Berlin, Germany

YD and I-KW contributed equally

Correspondence to

Yong Du;

duy@rki.de

\section{ABSTRACT}

Objectives: The use and combined use of psychotropic drugs and alcohol among older adults is a growing public health concern and should be constantly monitored. Relevant studies are scarce in Germany. Using data of the most recent national health survey, we analyse prevalence and correlates of psychotropic drug and alcohol use among this population.

Methods: Study participants were people aged 6079 years $(\mathrm{N}=2508)$ of the German Health Interview and Examination Survey for Adults 2008-2011. Medicines used during the last 7 days were documented. Psychotropic drugs were defined as medicines acting on the nervous system (ATC code N00) excluding anaesthetics (N01), analgesics/antipyretics (N02B), but including opiate codeines used as antitussives (R05D). Alcohol consumption in the preceding 12 months was measured by frequency (drinking any alcoholcontaining beverages at least once a week/a day) and quantity (alcohol consumed in grams/day; cut-offs: 10/ $20 \mathrm{~g} /$ day for women/men defining moderate and risky drinking). SPSS complex sample module was used for analysis.

Results: $21.4 \%$ of study participants use psychotropic medications, $66.9 \%$ consume alcohol moderately and $17.0 \%$ riskily, $51.0 \%$ drink alcohol at least once a week and $18.4 \%$ daily, $2.8 \%$ use psychotropic drugs combined with daily alcohol drinking. Among psychotropic drug users, $62.7 \%$ consume alcohol moderately, $14.2 \%$ riskily. The most frequently used psychotropic medications are antidepressants (7.9\%) and antidementia (4.2\%). Factors associated with a higher rate of psychotropic drug use are female sex, worse health status, certified disability and polypharmacy. Risky alcohol consumption is positively associated with male sex, smoking, upper social class, better health status, having no disability and not living alone.

Conclusions: Despite the high risk of synergetic effects of psychotropic drugs and alcohol, a substantial part of older psychotropic drug users consume alcohol riskily and daily. Health professionals should talk about the additional health risks of alcohol consumption when prescribing psychotropic drugs to older adults.

\section{Strengths and limitations of this study}

- A large sample of concurrent data on medication use, sociodemographic and health characteristics allows analyses of psychotropic drug and alcohol use on a population representative level.

- The short observation period (7 days) minimises recall bias concerning medication use, and quality control is ensured by checking original packages.

- Alcohol consumption was measured by frequency and quantity.

- The use of psychotropic drugs is likely to be underestimated as people who are institutionalised and those with severe disease and psychiatric disorders (including cognitive impairments, depression, dementia, etc) are less likely to participate in national health surveys.

- Under-reporting of alcohol use is possible as people tend to answer questions concerning intoxicating substances according to social desirability.

\section{INTRODUCTION}

Psychotropic drugs such as antidepressants, sedatives or hypnotics are characterised by their impact on the central nervous system (CNS) and influence perception, mood, consciousness or behaviour. They are established clinical treatments for a variety of neurological and mental diseases but also harbour risks of side effects and the development of dependency. Older adults, due to the loss of close persons, social networks or autonomy, may suffer from emotional and mental disorders and are a major group of psychotropic drug users. ${ }^{2}$ Nevertheless, the use of psychotropic medications by older adults should be considered carefully. Older adults are particularly vulnerable to drug-related adverse health consequences due to significant changes in pharmacokinetic and 
pharmacodynamic properties of drugs related to ageing processes. ${ }^{3}$ Additionally, an age-related increase in multimorbidity and polypharmacy among older adults aggravates those risks. ${ }^{4}$

Alcohol is a substance with psychotropic characteristics and also widely consumed by older adults. Sharing the same metabolic enzymes with psychotropic drugs, alcohol is broken down mainly in the liver. ${ }^{5}$ The intake of alcohol alters the activity of the metabolic enzymes and may result in pharmacokinetic and pharmacodynamic interactions with psychotropic drugs. ${ }^{5}$ Combined use of psychotropic drugs with alcohol, even in small amounts, can produce synergistic effects and therefore may be harmful and risky for older adults. ${ }^{5}{ }^{6}$ For example, alcohol enhances the sedative effects of frequently used antidepressants, benzodiazepines and sleep medications, ${ }^{5}$ increasing greatly the risks of falls and hip fractures. ${ }^{7}$ The use of alcohol and psychotropic drugs among older adults, particularly combined use of both, constitutes a growing public health concern and should be constantly monitored and carefully reviewed over time. $^{8}$

Psychotropic drug use and alcohol consumption have been investigated previously in the general adult population or in studies regarding alcohol-interactive medication use. ${ }^{9-12}$ Only a few studies investigated specifically the use of psychotropic drugs and alcohol among older adults. ${ }^{12-14}$ Our own previous study, which also investigated the use of psychotropic drugs and alcohol among older adults, was conducted using data of a national health survey from $1998 .{ }^{14}$ An update is needed, given significant changes in demographics, health behaviour as well as disease profiles over the last decade.

With the recent data of the German Health Interview and Examination Survey for Adults 2008-2011, we analyse prevalence and correlates of psychotropic medicine use and alcohol consumption as well as the concomitant use of both among older people.

\section{METHODS}

Study design and participants

As database for the present study served the German Health Interview and Examination Survey for Adults, wave 1 (DEGS1), which was conducted by the Robert Koch Institute from November 2008 to December 2011. DEGS1 aims to provide representative data on the health of adults aged 18-79 years living in Germany. Details of the study design, sampling strategy and protocol have been published elsewhere. ${ }^{15}$ Briefly, a twostage, probability-cluster sampling procedure was applied. A sample of 180 primary sample units, representative of municipality sizes and structures in Germany, were selected. In the second stage, random samples were drawn from local population registries stratified by age and sex. The final sample aged 1879 years with completed interview and examination data amounted to 7115 adults. $^{15} 16$
For the present analyses, only participants aged 6079 years with complete interview and examination data were included, resulting in a total of 2508 participants (1277 women, 1231 men) (table 1 ).

DEGS1 was approved by the Federal and State Commissioners for Data Protection and the Charité-Universitätsmedizin Berlin ethics committee (number EA2/047/08). Survey participants provided written informed consent prior to interviews and examinations.

\section{Data collection}

Data collection in DEGS1 was conducted via selfadministered questionnaires, standardised physicianadministered computer-assisted personal interviews (CAPI), standardised personal interviews on medicine usage, medical examinations, physiological measurements and laboratory tests. ${ }^{15}$

Self-administered questionnaires were used to collect data on sociodemographic characteristics (age, sex, region of residence), individual information on household size (number of persons living in household), income, profession and educational attainment, health-related behaviour (such as tobacco use), dietary and nutritional habits (including alcohol consumption), self-rated health status and officially certified disability. ${ }^{15}$

Detailed information on medication use was recorded by trained health professionals. In the invitation letter, participants were asked to bring the original packages of all medications-prescribed and Over-The-Counter (OTC) products-used during the past 7 days to the examination site for the purpose of documentation and verification. This permitted automated recording of unique product identifiers and drug coding according to the WHO 'Anatomical Therapeutic Chemical' (ATC) classification system. ${ }^{17}$

\section{Defining psychotropic drug use and measuring alcohol consumption}

In the present study, we included psychotropic drugs belonging to the nervous system class (ATC code N00) as well as opiates used as antitussives (ATC code R05DA) and aspirin-caffeine combination preparations (ATC code N02BA71) considering their CNS effects. ${ }^{14}$ We excluded other analgesics and antipyretics such as aspirin and paracetamol (ATC code N02B), local anaesthetics (ATC code N01B), homeopathic drugs of the ATC class N00 and drugs with indistinct active ingredients. ${ }^{14}$ Psychotropic drugs with herbal active ingredients were considered and coded separately under specific subgroups.

Alcohol consumption during the preceding 12 months was recorded via a standardised food-frequency questionnaire. We asked each survey participant 'How often have you taken these alcohol-containing beverages over the last 12 months?'differentiating according to the type of alcoholic beverages (namely 'beer', 'wine, champagne, fruit wine', 'cocktail and other alcohol-containing mixtures' and 
Table 1 Study population, prevalence of psychotropic drug use and alcohol consumption among adults aged 60-79 years by sociodemographic and health-related factors: German Health Interview and Examination Survey for Adults (DEGS1) 2008-2011

\begin{tabular}{|c|c|c|c|c|c|c|c|c|c|c|c|c|}
\hline & \multicolumn{2}{|c|}{$\begin{array}{l}\text { Study } \\
\text { population }\end{array}$} & \multicolumn{2}{|c|}{$\begin{array}{l}\text { Psychotropic drug } \\
\text { use }(n=518)\end{array}$} & \multicolumn{4}{|c|}{ Alcohol consumption-by frequency } & \multicolumn{4}{|c|}{ Alcohol consumption-by quantity } \\
\hline & \multirow[b]{2}{*}{$\mathbf{N}$} & \multirow[b]{2}{*}{ Per cent } & \multirow[b]{2}{*}{ Per cent } & \multirow[b]{2}{*}{$95 \% \mathrm{Cl}$} & \multicolumn{2}{|c|}{$\begin{array}{l}\text { At least once a week } \\
(n=1295)\end{array}$} & \multicolumn{2}{|c|}{$\begin{array}{l}\text { At least once a day } \\
(n=468)\end{array}$} & \multicolumn{2}{|c|}{$\begin{array}{l}\text { Moderate drinking } t \\
(n=1659)\end{array}$} & \multicolumn{2}{|c|}{$\begin{array}{l}\text { Risky drinking } \\
(\mathrm{n}=459)\end{array}$} \\
\hline & & & & & Per cent & $95 \% \mathrm{Cl}$ & Per cent & $95 \% \mathrm{Cl}$ & Per cent & $95 \% \mathrm{CI}$ & Per cent & $95 \% \mathrm{CI}$ \\
\hline Total & 2508 & 100.0 & 21.4 & 19.3 to 23.7 & 51.0 & 48.1 to 53.9 & 18.4 & 16.3 to 20.7 & 66.9 & 64.1 to 69.5 & 17.0 & 14.9 to 19.2 \\
\hline \multicolumn{13}{|l|}{ Sex } \\
\hline Men & 1231 & 46.9 & 15.9 & 13.2 to 18.9 & $68.4^{\star \star}$ & 64.8 to 71.8 & $29.7^{\star \star}$ & 26.2 to 33.4 & 67.3 & 63.7 to 70.7 & $23.9^{* \star}$ & 20.7 to 27.3 \\
\hline Women & 1277 & 53.1 & $26.3^{\star \star}$ & 23.2 to 29.7 & 35.2 & 31.8 to 38.9 & 8.1 & 6.4 to 10.2 & 66.5 & 62.6 to 70.2 & 10.9 & 9.0 to 13.2 \\
\hline \multicolumn{13}{|l|}{ Age group, years } \\
\hline $60-69$ & 1398 & 52.5 & 18.1 & 15.5 to 21.1 & 52.9 & 49.1 to 56.7 & 18.9 & 16.1 to 22.0 & 64.4 & 61.0 to 67.7 & 18.8 & 16.0 to 22.0 \\
\hline $70-79$ & 1110 & 47.5 & $25.1^{*}$ & 21.4 to 29.1 & 48.8 & 44.9 to 52.7 & 17.8 & 15.1 to 21.0 & $69.7^{*}$ & 65.5 to 73.6 & 14.8 & 12.1 to 18.0 \\
\hline \multicolumn{13}{|l|}{ Region of residence§ } \\
\hline Northern Germany & 644 & 25.8 & 19.4 & 15.4 to 24.1 & 42.4 & 36.6 to 48.3 & 14.5 & 11.0 to 18.8 & 66.2 & 60.7 to 71.3 & 16.8 & 12.6 to 22.0 \\
\hline Central Germany & 1141 & 41.3 & 22.0 & 19.0 to 25.3 & 49.1 & 45.2 to 53.0 & 16.4 & 13.6 to 19.7 & 69.1 & 65.5 to 72.5 & 12.8 & 10.8 to 15.2 \\
\hline Southern Germany & 723 & 32.9 & 22.3 & 18.4 to 26.8 & $60.2^{* *}$ & 55.7 to 64.6 & $24.0^{*}$ & 20.0 to 28.4 & 64.7 & 59.1 to 69.9 & $22.3^{\star \star}$ & 18.3 to 26.9 \\
\hline \multicolumn{13}{|l|}{ Social status } \\
\hline Lower & 436 & 24.1 & $25.4^{\star}$ & 20.6 to 30.9 & 39.4 & 33.3 to 45.8 & 16.2 & 12.1 to 21.4 & 65.2 & 58.4 to 71.4 & 12.8 & 9.2 to 17.4 \\
\hline Middle & 1489 & 59.3 & 21.4 & 18.6 to 24.4 & 51.3 & 47.5 to 55.0 & 17.9 & 15.3 to 20.7 & 67.8 & 64.5 to 70.8 & 16.0 & 13.6 to 18.7 \\
\hline Upper & 562 & 16.5 & 15.3 & 12.0 to 19.4 & $65.7^{* *}$ & 59.8 to 71.1 & 23.3 & 19.2 to 27.9 & 67.2 & 61.8 to 72.2 & $26.3^{\star \star}$ & 21.6 to 31.7 \\
\hline \multicolumn{13}{|l|}{ Living alone } \\
\hline Yes & 507 & 21.3 & $27.7^{*}$ & 22.7 to 33.4 & 36.0 & 29.8 to 42.7 & 9.9 & 7.2 to 13.5 & 62.5 & 56.3 to 68.3 & 12.0 & 8.9 to 16.0 \\
\hline No & 1987 & 78.7 & 19.6 & 17.4 to 22.2 & $55.0^{\star *}$ & 51.9 to 58.1 & $20.6^{\star *}$ & 18.1 to 23.4 & 68.3 & 65.4 to 71.1 & $18.2^{\star \star}$ & 16.0 to 20.7 \\
\hline \multicolumn{13}{|l|}{ Smoking } \\
\hline Smoker & 302 & 12.5 & 17.7 & 12.7 to 24.0 & 53.0 & 45.1 to 60.7 & $30.4^{\star *}$ & 23.7 to 38.0 & $55.5^{\star \star}$ & 48.4 to 62.5 & $26.2^{\star *}$ & 19.9 to 33.7 \\
\hline Ex-smoker & 927 & 36.3 & 21.0 & 17.6 to 24.9 & $60.7^{\star *}$ & 56.0 to 65.1 & 21.7 & 18.3 to 25.7 & 66.1 & 61.7 to 70.2 & 21.4 & 17.9 to 25.4 \\
\hline Never-smoker & 1265 & 51.2 & 22.1 & 19.0 to 25.6 & 44.2 & 40.4 to 48.1 & 13.3 & 11.0 to 16.0 & 70.6 & 66.5 to 74.4 & 11.7 & 9.7 to 14.1 \\
\hline \multicolumn{13}{|l|}{ Health status } \\
\hline Better & 1503 & 58.2 & 13.1 & 11.0 to 15.5 & $55.7^{* *}$ & 52.0 to 59.4 & $20.9^{*}$ & 18.1 to 24.0 & 67.1 & 63.4 to 70.6 & $19.8^{\star \star}$ & 16.9 to 23.1 \\
\hline Worse & 986 & 41.8 & $32.5^{\star *}$ & 28.7 to 36.6 & 44.3 & 40.2 to 48.5 & 14.8 & 12.2 to 17.8 & 66.6 & 62.7 to 70.3 & 13.0 & 10.9 to 15.5 \\
\hline \multicolumn{13}{|l|}{ Certified disability } \\
\hline Yes & 649 & 29.1 & $30.6^{\star *}$ & 26.0 to 35.5 & 47.8 & 42.1 to 53.6 & 14.8 & 11.6 to 18.7 & 66.9 & 62.2 to 71.3 & 13.5 & 10.4 to 17.4 \\
\hline No & 1801 & 70.9 & 17.2 & 15.1 to 19.6 & 52.4 & 49.2 to 55.6 & $19.8^{*}$ & 17.4 to 22.4 & 66.9 & 63.8 to 69.8 & 18.4 & 16.2 to 20.9 \\
\hline \multicolumn{13}{|l|}{ Polypharmacyף } \\
\hline Yes & 771 & 30.7 & $37.8^{\star *}$ & 33.8 to 42.1 & 46.5 & 42.4 to 50.7 & 17.6 & 14.8 to 20.8 & 67.7 & 63.7 to 71.4 & 14.5 & 12.2 to 17.3 \\
\hline No & 1730 & 69.3 & 9.4 & 7.5 to 11.8 & $54.3^{\star \star}$ & 50.7 to 57.9 & 19.1 & 16.2 to 22.3 & 66.5 & 63.0 to 69.9 & $18.7^{*}$ & 16.0 to 21.8 \\
\hline \multicolumn{13}{|c|}{ 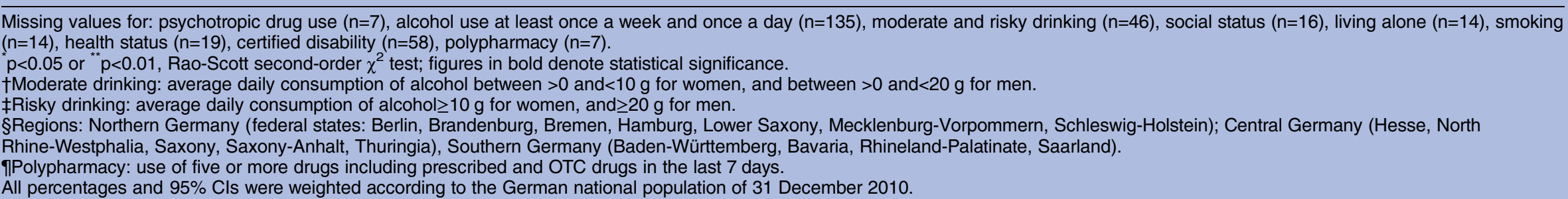 } \\
\hline
\end{tabular}

All percentages and 95\% Cls were weighted according to the German national population of 31 December 2010. 
'spirits'). Eleven possible answer choices were provided ranging from 'never' to 'more than five times daily'. Based on frequency of alcohol consumption, participants were classified as 'at least once a week' ('one to two times a week', 'three to four times a week', 'five to six times a week', 'once daily', to 'more than five times daily')—or 'daily' ('once daily', 'two times daily', 'three times daily', 'four to five times daily', 'more than five times daily') alcohol users.

For each consumed alcohol-containing beverage, the estimated volume (for beverages with high percentage of alcohol, this would be gauged to the nearest $2 \mathrm{cL}$ ) was recorded. The mean amount of alcohol consumed every day (grams per day) was computed for each survey participant by multiplying the frequency and amount of alcohol in grams contained in the consumed drinks according to methods previously described. ${ }^{18}$ Internationally, limits for risky alcohol consumption vary widely and do not differentiate according to age. ${ }^{19}$ In Germany, the threshold for risky drinking is set at $\geq 10$ $12 \mathrm{~g}$ /day of alcohol for women and $\geq 20-24 \mathrm{~g}$ /day for men. ${ }^{20} 21$ Considering our study participants were 60 years and older-and in the absence of age-specific limits-we adopted the lower limits of $\geq 10 \mathrm{~g}$ /day for women and $\geq 20 \mathrm{~g} /$ day for men to classify risky drinking. ${ }^{14}$ Moderate drinking was then defined as consumption of alcohol between $>0$ and $<10 \mathrm{~g} /$ day for women, and between $>0$ and $<20 \mathrm{~g} /$ day for men.

\section{Covariables}

Sociodemographic variables included sex, age and region of residence, social status and household size. Age groups included were 60-69 and 70-79 years. Regarding the region of residence, we considered the possible geographical differences in alcohol consumption among people in Germany and grouped the regions into three areas with each including several federal states: Northern Germany (Berlin, Brandenburg, Bremen, Hamburg, Lower Saxony, Mecklenburg-Vorpommern and Schleswig-Holstein); Central Germany (Hesse, North Rhine-Westphalia, Saxony, Saxony-Anhalt and Thuringia) and Southern Germany (Baden-Württemberg, Bavaria, Rhineland-Palatinate and Saarland). Socioeconomic status (SES) was classified as lower, middle and upper using an established index, including information on education, professional status and household income. ${ }^{22}$ Household size was categorised as living alone if only one single person was reported in a household.

Health-related variables included smoking status, selfperceived health status, having a certified disability and polypharmacy. Smoking status was assessed using four categories, namely 'yes, daily', 'yes, occasionally', 'ex-smoker' and 'never smoker'. For the present analyses, we classified smokers as those who answered 'yes, occasionally' and 'yes, daily', while the other two categories remained unchanged. Information on self-perceived health status was also collected via selfadministered questionnaires. The possible five answer choices were dichotomised as 'better' (very good or good) and 'worse' (fair, bad or very bad). Additionally, people were asked, if they had an officially certified disability (yes/no). Polypharmacy was assumed if five or more medicines (prescription and/or OTC) were used in the past 7 days. Additionally, for the purpose of conducting sensitivity analyses, we defined polypharmacy by (1) counting the number of prescription drugs only and (2) excluding psychotropic drugs.

\section{Statistical analyses}

All statistical analyses were performed using SPSS statistical software (V.20.0, SPSS, Chicago, Illinois, USA). In order to adjust for sample clustering effects, the SPSS complex samples module was used for all analyses. Sampling weights were used to correct deviations in the sample from the structure of the German general population of 31 December 2010 with respect to age, sex, region of residence, type of municipality, nationality and educational level. ${ }^{16}$

Descriptive statistics were used to examine characteristics of the study population. Weighted prevalence rates of psychotropic drug use, alcohol consumption and combined use of both substances were estimated and stratified according to above described covariables. Differences in the prevalence estimates between subgroups were tested by second-order Rao-Scott $\chi^{2}$ tests. ORs and 95\% CIs were derived from multivariable logistic regression models with psychotropic drug use, alcohol consumption and combined use of both substances as dependent variables and all covariables as predictive variables. We also looked at the association of body mass index (BMI) and sports activities with psychotropic drug use and alcohol consumption. We repeated the regression analyses adding BMI $(<25,25-30$, $\geq 30 \mathrm{~kg} / \mathrm{m}^{2}$ ) and sports activities (no sports, $<2$ hours/ week and $\geq 2$ hours/week in the past 3 months) in models. Both were not significantly associated with psychotropic drug use-overall and in major subgroupsand alcohol consumption (data not shown). For each variable, weighted proportion and unweighted $n$ depict the number of participants with complete information. The number of persons with missing values was explicitly stated for each variable with a range of $0.3 \% \quad(n=7)$ for psychotropic drug use, $1.8 \% \quad(\mathrm{n}=48)$ for risky alcohol drinking, to $5.4 \%(\mathrm{n}=135)$ for daily alcohol drinking. Persons with missing values were excluded from the analyses, with pairwise deletion for descriptive and listwise deletion for multivariable analyses. A probability level for statistically significant group differences was considered at $\mathrm{p}<0.05$ based on two-sided tests.

\section{RESULTS}

Our study includes 2508 people aged $60-79$ years, with an almost equal proportion of women and men. Half of our study participants are never-smokers, one-quarter resides in Northern Germany and every fourth has a 
lower SES. Nearly $60 \%$ of the participants perceive their health status as 'better', about $30 \%$ report having a certified disability or being exposed to polypharmacy and about $20 \%$ of older adults live alone (table 1 ).

Overall, $21.4 \%$ of all study participants use at least one psychotropic medication, $66.9 \%$ consume alcohol moderately and $17.0 \%$ riskily. About $51.0 \%$ of older adults drink alcohol at least once a week, while $18.4 \%$ are daily alcohol consumers (table 1).

Stratified by sociodemographic and health-related covariables, a significantly higher prevalence rate of psychotropic drug use is found among women, the older age group (70-79 years), people with a lower social status, those living alone, people with a worse health status, those having a certified disability and participants with polypharmacy. In contrast, a significantly higher prevalence rate of weekly alcohol use is found among men, people residing in Southern Germany, those with an upper social status, people living with others, those with a good health status, smokers and people without polypharmacy. Similar results are found for daily and risky alcohol use (table 1). Concerning moderate drinking, higher prevalence rates are found among the older age group (70-79 years), but lower rates are found among current smokers (table 1).

Table 2 depicts the use of psychotropic drugs according to specific subgroups. In total, 518 older participants consume 740 psychotropic drugs. Of these

Table 2 Use of psychotropic drugs according to specific subgroups among adults aged 60 and 79 years: German Health Interview and Examination Survey for Adults (DEGS1) 2008-2011

\begin{tabular}{|c|c|c|c|c|c|}
\hline \multirow[b]{2}{*}{ ATC code } & \multirow{2}{*}{$\begin{array}{l}\text { Medication class/active } \\
\text { pharmaceutical ingredient }\end{array}$} & \multirow[b]{2}{*}{ No. of drugs } & \multirow[b]{2}{*}{ No. of users } & \multicolumn{2}{|c|}{ User prevalence } \\
\hline & & & & Per cent & $95 \% \mathrm{Cl}$ \\
\hline Synthetics & & 571 & 404 & 16.9 & 14.9 to 19.1 \\
\hline N02A & Narcotic analgesics & 104 & 96 & 4.1 & 3.2 to 5.3 \\
\hline N02AX51 & Tilidin & 31 & 30 & 1.3 & 0.8 to 2.0 \\
\hline No2AX02 & Tramadol & 26 & 26 & 0.9 & 0.6 to 1.5 \\
\hline N02C & Antimigraine preparations & 7 & 7 & 0.4 & 0.2 to 1.0 \\
\hline N03 & Antiepileptics & 70 & 63 & 2.3 & 1.7 to 3.3 \\
\hline N03AF01 & Carbamazepin & 19 & 17 & 0.7 & 0.3 to 1.5 \\
\hline N03AX12 & Gabapentin & 17 & 17 & 0.6 & 0.3 to 1.2 \\
\hline No3AX16 & Pregabalin & 15 & 13 & 0.4 & 0.2 to 0.8 \\
\hline N04 & Antiparkinsonian agents & 47 & 32 & 1.2 & 0.7 to 2.0 \\
\hline No4BA11 & Levodopa and benserazide & 18 & 16 & 0.7 & 0.3 to 1.4 \\
\hline N05A & Antipsychotics & 24 & 21 & 0.8 & 0.5 to 1.2 \\
\hline N05B & Anxiolytics & 48 & 48 & 2.2 & 1.5 to 3.1 \\
\hline N05BA & Benzodiazepine derivatives & 46 & 46 & 2.1 & 1.4 to 3.1 \\
\hline N05BA08 & Bromazepam & 15 & 15 & 0.9 & 0.5 to 1.8 \\
\hline N05C & Hypnotics and sedatives & 52 & 42 & 1.3 & 0.9 to 1.9 \\
\hline N05CD & Benzodiazepines & 11 & 11 & 0.4 & 0.2 to 0.9 \\
\hline N05CF & Benzodiazepine-related drugs & 28 & 28 & 0.8 & 0.5 to 1.3 \\
\hline N06A & Antidepressants & 169 & 151 & 6.7 & 5.5 to 8.5 \\
\hline No6AA & Non-selective monoamine reuptake inhibitors & 82 & 80 & 3.8 & 2.8 to 5.3 \\
\hline No6AA09 & Amitriptylin & 26 & 25 & 1.4 & 0.8 to 2.3 \\
\hline N06AA05 & Opipramol & 21 & 21 & 1.1 & 0.5 to 2.2 \\
\hline No6AB & Selective serotonin reuptake inhibitors (SSRIs) & 47 & 47 & 2.0 & 1.4 to 2.7 \\
\hline No6AB04 & Citalopram & 29 & 29 & 1.0 & 0.7 to 1.6 \\
\hline N06B & Psychostimulants & 5 & 5 & 0.5 & 0.1 to 1.8 \\
\hline N06D & Antidementia drugs & 10 & 10 & 0.4 & 0.2 to 1.0 \\
\hline N07 & Others & 35 & 34 & 1.5 & 1.0 to 2.5 \\
\hline Phytomedicines & & 169 & 158 & 6.5 & 5.4 to 7.8 \\
\hline N06DP01 & Ginkgo biloba & 89 & 88 & 3.8 & 3.0 to 4.8 \\
\hline N06AP01 & St John's wort & 27 & 27 & 1.1 & 0.8 to 1.7 \\
\hline N05CP01/06 & Valerian & 44 & 42 & 1.5 & 1.0 to 2.1 \\
\hline N05CP04/05/08 & Others used for sleep & 9 & 9 & 0.4 & 0.1 to 1.0 \\
\hline \multicolumn{6}{|c|}{ Specific drug classes of interest } \\
\hline \multicolumn{2}{|c|}{ Antidepressants (N06A synthetics and St John's wort) } & 196 & 173 & 7.9 & 6.5 to 9.5 \\
\hline \multicolumn{2}{|c|}{ Antidementia drugs (N06D synthetics and Ginkgo biloba) } & 99 & 97 & 4.2 & 3.3 to 5.4 \\
\hline \multicolumn{2}{|c|}{$\begin{array}{l}\text { Hypnotics and sedatives (N05C synthetics, valerian and others } \\
\text { used for sleep) }\end{array}$} & 105 & 98 & 3.3 & 2.6 to 4.3 \\
\hline \multicolumn{2}{|c|}{ Benzodiazepines (N05BA, N05CD, N03AE01, N05CF) } & 86 & 84 & 3.3 & 2.5 to 4.4 \\
\hline \multicolumn{2}{|c|}{ All psychotropic drugs (synthetics and phytomedicines) } & 740 & 518 & 21.4 & 19.3 to 23.7 \\
\hline
\end{tabular}


drugs, $571(77.2 \%)$ are synthetics, while $169(22.8 \%)$ are phytomedicines. The user prevalence for synthetics and phytomedicines amounts to $16.9 \%$ and $6.5 \%$, respectively.

Among synthetic drugs, antidepressants are most frequently used $(6.7 \%)$, followed by narcotic analgesics $(4.1 \%)$, antiepileptics $(2.3 \%)$ and anxiolytics (2.2\%) (table 2). In contrast, synthetic antimigraine preparations, antidementia drugs, psycho-stimulants and antipsychotics are used by $<1 \%$ of the study population. The so-called Z-drugs under the ATC code N05CF (benzodiazepine-related drugs) account for the majority of hypnotics and sedatives (N05C) with a user prevalence rate of $0.8 \%$ (zopidem $0.5 \%$ and zopiclone $0.3 \%$, data not shown in table 2). Almost half of synthetic antidepressants are non-selective monoamine reuptake inhibitors, while selective serotonin reuptake inhibitors account for $27.8 \%$. Nearly, all anxiolytics originate from the medication group of benzodiazepine derivatives. About $3.3 \%$ of older adults use benzodiazepine or benzodiazepine-related drugs (table 2).

The most frequently used phytomedicines are Ginkgo biloba (3.8\%), followed by valerian $(1.5 \%)$ and St John's wort $(1.1 \%)$. Looking at the total of phytomedicine and synthetics use, antidepressants $(7.9 \%)$ and antidementia drugs $(4.2 \%)$ are the most frequently used psychotropic medications among older adults (table 2).

Table 3 describes the use of specific psychotropic drug groups of interest differentiated according to sociodemographic and health-related factors. A high use of synthetic medication, but not phytomedicines, is found among persons with a low social status and among those with a certified disability. People with a worse health status and those exposed to polypharmacy are significantly more likely to use any psychotropic drugs. Similarly, there is a greater probability of psychotropic medicine use among people with a certified disability (with exception of phytomedicines, hypnotics and sedatives and antidementia drugs).

Women are more likely to use all subgroups of psychotropic drugs with the exception of antiepileptics. People who live alone significantly more often use antidepressants and antidementia drugs, while people with a lower social status are more likely to use narcotic analgesics. The region of residence and smoking status are less likely to be associated with the use of subgroups of psychotropic drugs except that ex-smokers are significantly more likely to use antiepileptics (table 3).

Figure 1 depicts psychotropic drug use in relation to daily and risky alcohol drinking. Approximately two-thirds $(75.5 \%)$ of those who drink daily also drink riskily with a prevalence rate of $13.9 \%$ (areas A6 and A5). Among those who drink daily, only one-fifth (20.9\%) do not drink riskily and do not use psychotropic drugs (area A3). The prevalence of psychotropic drug use combined with daily alcohol drinking amounts to $2.8 \%$ (areas A5 and A2), the majority of this group drinks also riskily (area A5, prevalence $2.1 \%$ ).
The proportions of alcohol users according to frequency and volume of alcohol use and stratified by specific psychotropic drug groups are shown in table 4 . The majority of all psychotropic drug users $(62.7 \%)$ drink alcohol moderately, while $14.2 \%$ drink riskily. Nearly half of psychotropic drug users $(45.7 \%)$ drink alcohol at least once a week, while $12.9 \%$ drink alcohol daily. There are no significant differences within the subgroups of alcohol consumption in relation to the subgroups of psychotropic drugs (table 4).

Table 5 presents factors associated with psychotropic drug, alcohol and the combined use of both substances. Polypharmacy and female sex are correlates of psychotropic drug use, overall and for major subgroups of interest. Correlates of daily drinking combined with psychotropic drug use are worse health status and polypharmacy. In contrast, male sex and residing in Southern Germany are predictors for alcohol use. Lower social status, worse health status, disability and living alone are adversely associated with any alcohol drinking or risky drinking, whereas positively associated with any psychotropic drug use or specific subgroups (antidepressants and narcotic analgesics). Older age (70-79 years) is associated with the use of phytomedicine only, while ex-smokers are more likely to use phytomedicines, hypnotics and sedatives and to practice risky alcohol consumption (table 5). Sensitivity analyses involving polypharmacy defined by including prescription drugs only show no substantial changes. Sensitivity analyses involving polypharmacy without psychotropic medicines show that the associations between polypharmacy and any psychotropic drug use are attenuated while the statistical significance remains unchanged (OR 1.88, 95\% CIs 1.42 to $2.48, \mathrm{p}<0.0001)$. Also, the associations of polypharmacy with daily or risky alcohol drinking remain non-significant (data not shown).

\section{DISCUSSION}

The present study provides representative data on psychotropic drug use and alcohol consumption among adults aged 60-79 years in Germany. About $21.4 \%$ of older adults use at least one psychotropic medication in the past 7 days, more than half consume any alcohol-containing beverage, about $17-18 \%$ practice daily and/or risky alcohol drinking, and $2.8 \%$ use psychotropic drugs combined with daily alcohol drinking. More than half of those who use any psychotropic drugs consume alcohol moderately or at least once a week, while about $13-14 \%$ consumes alcohol daily or riskily. Factors associated with a higher rate of psychotropic drug use are female sex, worse health status, certified disability and polypharmacy. Correlates of higher rates of alcohol consumption are male sex, living in Southern Germany, upper social class, having a good health status and not living alone.

Using the same methods, our previous study based on data from 1998 finds prevalence rates of psychotropic 
Table 3 Prevalence of specific psychotropic drugs' use among adults aged 60-79 years by sociodemographic and health-related factors: German Health Interview and Examination Survey for Adults (DEGS1) 2008-2011

\begin{tabular}{|c|c|c|c|c|c|c|c|c|c|c|c|c|c|c|c|c|}
\hline & \multicolumn{2}{|c|}{ Synthetic medicines } & \multicolumn{2}{|c|}{ Phytomedicines } & \multicolumn{2}{|c|}{ Antidepressants $\dagger$} & \multicolumn{2}{|c|}{$\begin{array}{l}\text { Hypnotics and } \\
\text { sedatives } \neq\end{array}$} & \multicolumn{2}{|c|}{$\begin{array}{l}\text { Narcotic } \\
\text { analgesics§ }\end{array}$} & \multicolumn{2}{|c|}{$\begin{array}{l}\text { Benzodiazepines } \\
\text { and related drugs } \|\end{array}$} & \multicolumn{2}{|c|}{$\begin{array}{l}\text { Antidementia } \\
\text { drugs }^{\star \star}\end{array}$} & \multicolumn{2}{|c|}{ Antiepilepticst† } \\
\hline & Per cent & $95 \% \mathrm{Cl}$ & Per cent & $95 \% \mathrm{Cl}$ & Per cent & $95 \% \mathrm{Cl}$ & Per cent & $95 \% \mathrm{Cl}$ & Per cent & $95 \% \mathrm{Cl}$ & Per cent & $95 \% \mathrm{Cl}$ & Per cent & $95 \% \mathrm{Cl}$ & Per cent & $95 \% \mathrm{Cl}$ \\
\hline \multicolumn{17}{|l|}{ Sex } \\
\hline Men & 13.1 & 10.8 to 16.0 & 3.7 & 2.6 to 5.1 & 3.4 & 2.4 to 4.8 & 1.6 & .9 to 2.6 & 3.3 & 2.0 to 5.3 & 1.7 & 1.0 to 2.8 & 3.1 & 2.0 to 4.7 & $3.2^{*}$ & 2.1 to 5.0 \\
\hline Women & $20.2^{\star *}$ & 17.3 to 23.5 & $9.0^{* *}$ & 7.2 to 11.2 & $11.8^{* *}$ & 9.4 to 14.7 & $4.9^{* *}$ & 3.7 to 6.6 & 4.9 & 3.6 to 6.5 & $4.7^{\star *}$ & 3.3 to 6.5 & 5.2 & 3.8 to 7.0 & 1.5 & 0.9 to 2.6 \\
\hline \multicolumn{17}{|l|}{ Age group, years } \\
\hline $60-69$ & 14.7 & 12.3 to 17.6 & 4.3 & 3.3 to 5.6 & 7.3 & 5.5 to 9.7 & 2.8 & 2.0 to 3.9 & 4.2 & 2.8 to 6.2 & 2.3 & 1.6 to 3.3 & 2.1 & 1.4 to 3.2 & 2.7 & 1.8 to 3.9 \\
\hline $70-79$ & $19.3^{*}$ & 15.9 to 23.1 & $8.9^{* *}$ & 7.0 to 11.4 & 8.5 & 6.3 to 11.3 & 4.0 & 2.8 to 5.7 & 4.1 & 3.0 to 5.7 & $4.4^{*}$ & 2.9 to 6.6 & $6.5^{* *}$ & 4.7 to 8.8 & 2.0 & 1.1 to 3.6 \\
\hline \multicolumn{17}{|l|}{ Region of residence $\ddagger \ddagger$} \\
\hline Northern Germany & 15.6 & 12.3 to 19.6 & 5.2 & 3.5 to 7.8 & 6.6 & 4.6 to 9.4 & 2.6 & 1.5 to 4.5 & 4.0 & 2.4 to 6.4 & 2.3 & 1.3 to 3.9 & 3.0 & 1.8 to 5.0 & 2.6 & 1.4 to 4.6 \\
\hline Central Germany & 16.1 & 13.3 to 19.4 & 7.7 & 5.9 to 10.0 & 7.5 & 5.5 to 10.0 & 3.7 & 2.6 to 5.4 & 4.0 & 2.8 to 5.6 & 3.7 & 2.5 to 5.3 & 5.2 & 3.7 to 7.4 & 1.9 & 1.2 to 3.2 \\
\hline Southern Germany & 18.9 & 15.0 to 23.5 & 6.0 & 4.3 to 8.2 & 9.4 & 6.7 to 12.9 & 3.4 & 2.2 to 5.3 & 4.5 & 2.7 to 7.4 & 3.6 & 2.0 to 6.4 & 3.8 & 2.4 to 5.9 & 2.6 & 1.4 to 4.9 \\
\hline \multicolumn{17}{|l|}{ Social status } \\
\hline Lower & $21.9^{*}$ & 17.2 to 27.4 & 4.4 & 2.7 to 7.1 & 8.4 & 5.6 to 12.4 & 3.0 & 1.7 to 5.5 & $7.3^{* *}$ & 4.9 to 10.7 & 4.0 & 2.2 to 7.2 & 3.1 & 1.6 to 5.9 & 1.8 & 0.8 to 4.2 \\
\hline Middle & 16.6 & 14.1 to 19.5 & 7.2 & 5.7 to 9.1 & 8.2 & 6.3 to 10.8 & 3.5 & 2.5 to 4.8 & 3.5 & 2.4 to 5.0 & 3.1 & 2.1 to 4.6 & 4.6 & 3.3 to 6.3 & 2.7 & 1.7 to 4.1 \\
\hline Upper & 10.4 & 7.8 to 13.9 & 6.8 & 4.6 to 9.9 & 5.5 & 3.7 to 8.1 & 3.4 & 2.0 to 5.9 & 1.9 & 1.1 to 3.5 & 3.0 & 1.6 to 5.5 & 4.0 & 2.5 to 6.4 & 1.6 & 0.7 to 3.8 \\
\hline \multicolumn{17}{|l|}{ Living alone } \\
\hline Yes & $22.4^{*}$ & 18.0 to 27.6 & $9.3^{*}$ & 6.2 to 13.6 & $14.2^{* *}$ & 10.4 to 19.1 & 3.4 & 1.9 to 5.8 & 5.2 & 3.3 to 8.2 & 5.0 & 2.8 to 8.9 & $7.0^{*}$ & 4.3 to 11.3 & 2.3 & 1.1 to 4.6 \\
\hline No & 15.4 & 13.2 to 17.9 & 5.7 & 4.5 to 7.1 & 6.1 & 4.7 to 7.9 & 3.3 & 2.5 to 4.4 & 3.9 & 2.8 to 5.3 & 2.8 & 2.0 to 3.9 & 3.4 & 2.5 to 4.5 & 2.3 & 1.6 to 3.4 \\
\hline \multicolumn{17}{|l|}{ Smoking } \\
\hline Smoker & 14.1 & 9.9 to 19.7 & 3.9 & 1.9 to 7.7 & 7.0 & 4.4 to 10.9 & 2.8 & 1.3 to 5.9 & 4.7 & 2.5 to 8.8 & 2.4 & 1.1 to 5.0 & 1.3 & .5 to 3.5 & 2.5 & 1.1 to 6.0 \\
\hline Ex-smoker & 16.1 & 13.0 to 19.6 & 6.9 & 5.1 to 9.4 & 5.8 & 4.1 to 8.2 & 3.8 & 2.5 to 5.7 & 5.3 & 3.4 to 8.3 & 2.7 & 1.6 to 4.7 & 4.2 & 2.8 to 6.2 & $3.5^{*}$ & 2.2 to 5.7 \\
\hline Never-smoker & 17.7 & 14.7 to 21.3 & 6.3 & 4.9 to 7.9 & 9.0 & 6.8 to 11.8 & 3.2 & 2.2 to 4.5 & 3.2 & 2.2 to 4.5 & 4.0 & 2.7 to 5.7 & 4.3 & 3.1 to 6.0 & 1.4 & 0.8 to 2.4 \\
\hline \multicolumn{17}{|l|}{ Health status } \\
\hline Better & 9.2 & 7.4 to 11.4 & 5.2 & 3.9 to 6.9 & 4.9 & 3.7 to 6.6 & 2.3 & 1.6 to 3.3 & 1.2 & 0.5 to 2.6 & 1.9 & 1.2 to 3.1 & 3.1 & 2.2 to 4.3 & 1.1 & 0.6 to 2.0 \\
\hline Worse & $27.3^{* *}$ & 23.7 to 31.3 & $8.2^{*}$ & 6.3 to 10.5 & $12.0^{\star *}$ & 9.3 to 15.3 & $4.8^{*}$ & 3.4 to 6.8 & $8.1^{\star *}$ & 6.2 to 10.6 & $5.2^{* *}$ & 3.6 to 7.5 & $5.4^{*}$ & 3.8 to 7.7 & $3.9^{* *}$ & 2.6 to 5.9 \\
\hline \multicolumn{17}{|l|}{ Certified disability } \\
\hline Yes & $27.3^{* *}$ & 23.1 to 32.1 & 6.1 & 4.1 to 9.2 & $11.6^{*}$ & 8.5 to 15.5 & 3.7 & 2.4 to 5.6 & $7.7^{* *}$ & 5.4 to 10.8 & $5.0^{*}$ & 3.2 to 7.7 & 4.7 & 2.8 to 8.0 & $5.0^{* *}$ & 3.1 to 7.9 \\
\hline No & 12.1 & 10.1 to 14.4 & 6.6 & 5.3 to 8.2 & 6.3 & 4.9 to 8.0 & 3.0 & 2.2 to 4.0 & 2.5 & 1.7 to 3.7 & 2.5 & 1.7 to 3.6 & 4.1 & 3.1 to 5.4 & 1.3 & 0.8 to 2.0 \\
\hline \multicolumn{17}{|l|}{ Polypharmacy§§ } \\
\hline Yes & $31.2^{* *}$ & 27.3 to 35.4 & $10.9^{* *}$ & 8.8 to 13.4 & $15.0^{* *}$ & 12.0 to 18.6 & $6.1^{* *}$ & 4.6 to 8.1 & $8.4^{* *}$ & 6.4 to 10.9 & $6.3^{* *}$ & 4.5 to 8.7 & $7.4 *$ & 5.5 to 9.9 & $4.6^{* *}$ & 3.1 to 6.7 \\
\hline No & 6.4 & 4.8 to 8.6 & 3.3 & 2.2 to 4.9 & 2.6 & 1.7 to 4.0 & 1.3 & 0.8 to 2.2 & 1.0 & 0.4 to 2.5 & 1.1 & 0.5 to 2.3 & 1.8 & 1.1 to 3.0 & 0.7 & 0.4 to 1.1 \\
\hline
\end{tabular}

${ }^{*} p<0.05$ or ${ }^{* *} p<0.01$, comparison within specific subgroup, the Rao-Scott second-order $\chi^{2}$ test. Figures in bold denote statistical significance.

Missing values for: social status $(n=16)$, living alone $(n=14)$, smoking $(n=14)$, health status $(n=19)$, certified disability $(n=58)$, polypharmacy $(n=7)$.

All percentages and $95 \%$ Cls were weighted according to the German national population of 31 December 2010 .

†N06A synthetics and St John's wort (N06AP01).

$\ddagger$ N05C synthetics, valerian and others used for sleep (N05CP).

§N02A.

IN05BA, N05CD, N03AE01 and N05CF.

${ }^{* \star}$ N06D synthetics and Ginkgo biloba (N06DP01)

††NO3.

łłRegions: Northern Germany (federal states: Berlin, Brandenburg, Bremen, Hamburg, Lower Saxony, Mecklenburg-Vorpommern, Schleswig-Holstein); Central Germany (Hesse, North

Rhine-Westphalia, Saxony, Saxony-Anhalt, Thuringia), Southern Germany (Baden-Württemberg, Bavaria, Rhineland-Palatinate, Saarland).

$\S \S$ Polypharmacy: use of five or more drugs, including prescribed and OTC drugs in the last 7 days. 


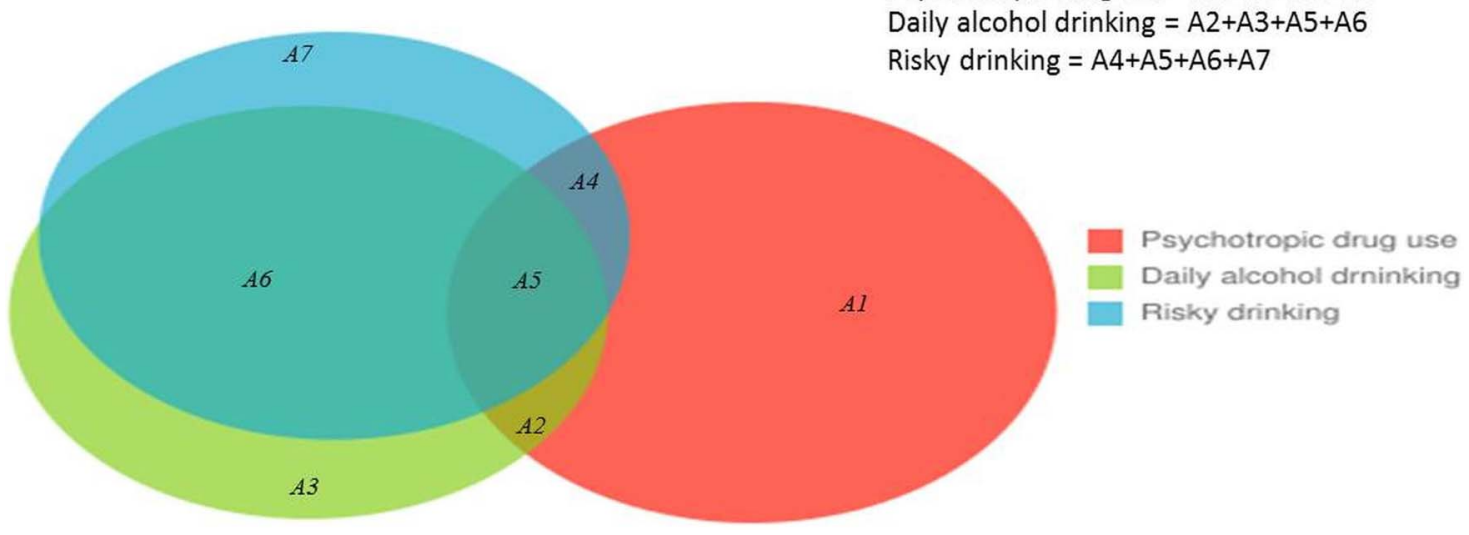

Figure 1 Prevalence of psychotropic drug use and alcohol consumption among adults aged 60-79 years. German Health Interview and Examination Survey for Adults (DEGS1) 2008-2011. A1, psychotropic drug use only, no alcohol use ( $\mathrm{n}=387$, $17.5 \%, 95 \% \mathrm{Cl} 15.5 \%$ to $19.6 \%$ ). A2, combined use of psychotropic drugs and alcohol (but not risky drinking) (n=17, $0.7 \%, 95 \%$ $\mathrm{Cl} 0.4 \%$ to $1.2 \%$ ). A3, daily alcohol use, but not risky drinking, no psychotropic drug use ( $\mathrm{n}=99,3.9 \%, 95 \% \mathrm{Cl} 2.9 \%$ to $5.1 \%$ ). A4, psychotropic drug use combined with risky drinking (but not daily) ( $\mathrm{n}=22,1.0 \%, 95 \% \mathrm{Cl} 0.6 \%$ to $1.7 \%$ ). A5, psychotropic drug use combined with daily risky drinking $(n=59,2.1 \%, 95 \% \mathrm{Cl} 1.5 \%$ to $2.9 \%)$. A6, daily risky alcohol drinking, but no psychotropic drug use $(\mathrm{n}=293,11.9 \%, 95 \% \mathrm{Cl} 10.3 \%$ to $13.7 \%)$. A7, risky drinking only, no daily alcohol use and no psychotropic drug use $(n=82,2.6 \%, 95 \% \mathrm{Cl} 1.9 \%$ to $3.5 \%)$. One hundred and forty-two persons with missing values for psychotropic drug use, risky drinking or daily alcohol drinking were excluded; 1407 non-users of psychotropic drugs who neither drink daily nor riskily are not shown in the figure. All percentages were weighted according to the German national population of 31 December 2010; Daily alcohol drinking, drinking of alcohol-containing beverages at least once a day; Risky drinking, average daily alcohol consumption of $\geq 20 \mathrm{~g}$ for men and $\geq 10 \mathrm{~g}$ for women.

drug use of $20.1 \%$, alcohol use of $47.3 \%$ and risky drinking of $15.1 \%,{ }^{14}$ which are comparable to findings of the present study. Yet, comparability of our results with other national and international studies is limited as there are great differences in study design, data collection, observational windows and definitions of psychotropic drugs and risky alcohol consumption.

A regional population-based study of health in the Pomeranian area of Germany reports that among adults aged $60-79$ years, $3.8 \%$ of men and $6.8 \%$ of women use sedatives, hypnotics or anxiolytics during the 7 days preceding the data collection. ${ }^{23}$ In our study, $3.3 \%(1.6 \%$ hypnotics and sedatives $+1.7 \%$ benzodiazepines) of the men and $9.6 \%$ (4.9\% hypnotics and sedatives $+4.7 \%$ benzodiazepines) of the women use sedatives, hypnotics and benzodiazepines and related drugs. The Pomeranian study includes more drugs of the substance groups sedatives, hypnotics or anxiolytics than our study. ${ }^{23}$ In our analyses, no use of barbiturates was included, while antiepileptic drugs and anxiolytics were analysed separately. The use of opioids with a prevalence rate of $0.9 \%$ in men and $1.6 \%$ in women in the Pomeranian study ${ }^{23}$ is lower than our findings of $3.3 \%$ in men and $4.9 \%$ in women. Higher values in our study could be based on differences in definition of opioids. Our study includes not only opioids used as analgesics but also as antitussives.

International population-based health surveys observe similar prevalence rates for the use of subgroups of psychotropic drugs as our study. The US National Health and Nutrition Examination Survey (NHANES) 20072012 finds a prevalence of opioid analgesics' use in the past 30 days of $7.9 \%$ (men $6.9 \%$, women $8.6 \%$ ) among adults aged 60 years and older. ${ }^{24}$ In the Australian National Survey of Mental Health and Well-being 2007, including the age group 65-74 years, the prevalence of any antidepressant use amounts to $7.4 \%$, and of anxiolytics, sedatives or hypnotics to $7.9 \%$ in the past 2 weeks. ${ }^{25}$ In a representative sample of community-dwelling adults aged 60 years and older in Ireland, regular exposure to CNS drugs include antidepressants (prevalence $7.4 \%$ ), hypnotics $(5.5 \%)$, anxiolytics $(2.7 \%)$ and opioid analgesics $(3.1 \%) .{ }^{10}$ A direct comparison of these findings with our results is impossible due to differences in the definition of psychotropic drugs (eg, phytomedicines are also considered in our study) and observation windows as well as study populations. Comparative studies, including Germany and other European countries, however, demonstrate that psychotropic drug use is generally lower among adults in Germany than in Western Europeanbut higher than in Eastern European countries. ${ }^{26-30}$

Patterns of alcohol consumption differ widely between countries and are influenced by drinking cultures and social norms. ${ }^{31}{ }^{32}$ Alcohol use is found to be consistently high among older adults with a range between $40 \%$ and $60 \%$ and a higher use in men than in women in Belgium, ${ }^{33}$ USA $^{9}{ }^{34}$ and Spain. ${ }^{35}$ Prevalence rates of risky drinking in international studies are difficult to compare because definitions of standard drinking size, alcohol consumption guidelines ${ }^{32}$ and definitions of 
Table 4 Alcohol consumption among psychotropic drug users aged 60-79 years-overall and in major subgroups: German Health Interview and Examination Survey for Adults (DEGS1) 2008-2011

\begin{tabular}{|c|c|c|c|c|c|c|c|c|c|c|c|c|c|}
\hline \multirow[b]{3}{*}{ Psychotropic drugs } & \multirow[b]{3}{*}{$\mathrm{N}$} & \multicolumn{6}{|c|}{ Alcohol consumption according to frequency } & \multicolumn{6}{|c|}{ Alcohol consumption according to quantity } \\
\hline & & \multicolumn{3}{|c|}{ At least once a week } & \multicolumn{3}{|c|}{ At least once a day } & \multicolumn{3}{|c|}{ Moderate drinking* } & \multicolumn{3}{|c|}{ Risky drinking† } \\
\hline & & $\mathrm{n}$ & $\%$ & $95 \% \mathrm{Cl}$ & $\mathrm{n}$ & $\%$ & $95 \% \mathrm{Cl}$ & $\mathrm{n}$ & $\%$ & $95 \% \mathrm{Cl}$ & $\mathrm{N}$ & $\%$ & $95 \% \mathrm{Cl}$ \\
\hline Any psychotropic drugs & 518 & 227 & 45.7 & 39.9 to 51.6 & 76 & 12.9 & 9.6 to 17.2 & 319 & 62.7 & 56.8 to 68.2 & 82 & 14.2 & 10.9 to 18.3 \\
\hline Antidepressants & 173 & 68 & 41.4 & 31.2 to 52.4 & 21 & 10.4 & 6.1 to 17.3 & 93 & 51.4 & 41.4 to 61.4 & 24 & 14.7 & 8.9 to 23.3 \\
\hline Hypnotics and sedatives & 98 & 47 & 50.1 & 37.5 to 62.6 & 15 & 17.0 & 8.8 to 30.3 & 57 & 62.4 & 49.8 to 73.5 & 19 & 18.7 & 11.3 to 29.5 \\
\hline Antidementia drugs & 97 & 43 & 44.2 & 31.1 to 58.1 & 15 & 13.5 & 7.3 to 23.8 & 67 & 68.9 & 56.4 to 79.2 & 13 & 11.3 & 5.7 to 21.0 \\
\hline Narcotic analgesics & 96 & 40 & 38.5 & 27.1 to 51.3 & 15 & 12.5 & 7.0 to 21.4 & 55 & 59.8 & 48.0 to 70.6 & 15 & 11.1 & 6.3 to 19.0 \\
\hline Benzodiazepines and related drugs & 84 & 36 & 46.8 & 32.4 to 61.7 & 7 & 7.7 & 3.0 to 18.4 & 50 & 62.2 & 46.2 to 75.9 & 12 & 14.1 & 6.0 to 29.6 \\
\hline Antiepileptics & 63 & 28 & 50.3 & 32.9 to 67.5 & 12 & 19.0 & 9.3 to 34.8 & 36 & 60.7 & 44.3 to 75.0 & 10 & 12.2 & 5.8 to 24.0 \\
\hline
\end{tabular}

${ }^{*}$ Men $>0$ and $<20 \mathrm{~g}$, women $>0$ and $<10 \mathrm{~g} /$ day.

tMen $\geq 20 \mathrm{~g}$, women $\geq 10 \mathrm{~g} /$ day.

All percentages were weighted according to the German national population of 31 December 2010

\begin{tabular}{|c|c|c|c|c|c|c|c|c|c|c|c|c|c|c|c|c|c|c|}
\hline \multirow[b]{4}{*}{$\mathbf{R}^{2}$} & \multicolumn{10}{|c|}{ Psychotropic drug use } & \multicolumn{6}{|c|}{ Alcohol consumption } & \multirow{2}{*}{\multicolumn{2}{|c|}{$\begin{array}{l}\text { Psychotropic drug } \\
\text { use combined } \\
\text { with daily drinking }\end{array}$}} \\
\hline & \multirow{2}{*}{\multicolumn{2}{|c|}{$\begin{array}{l}\text { Any psychotropic } \\
\text { drug } \\
0.213\end{array}$}} & \multirow{2}{*}{\multicolumn{2}{|c|}{$\begin{array}{l}\begin{array}{l}\text { All } \\
\text { phytomedicines }\end{array} \\
0.106\end{array}$}} & \multirow{2}{*}{\multicolumn{2}{|c|}{$\begin{array}{l}\text { All } \\
\text { antidepressants } \\
0.190\end{array}$}} & \multirow{2}{*}{\multicolumn{2}{|c|}{$\begin{array}{l}\text { All hypnotics and } \\
\text { sedatives } \\
0.120\end{array}$}} & \multirow{2}{*}{\multicolumn{2}{|c|}{$\begin{array}{l}\begin{array}{l}\text { Narcotic } \\
\text { analgesics }\end{array} \\
0.216\end{array}$}} & \multirow{2}{*}{\multicolumn{2}{|c|}{$\begin{array}{l}\begin{array}{l}\text { At least once a } \\
\text { week }\end{array} \\
0.209\end{array}$}} & \multirow{2}{*}{\multicolumn{2}{|c|}{$\begin{array}{l}\text { At least once a } \\
\text { day } \\
0.186\end{array}$}} & \multirow{2}{*}{\multicolumn{2}{|c|}{$\begin{array}{l}\text { Risky alcohol } \\
\text { drinking }\end{array}$}} & & \\
\hline & & & & & & & & & & & & & & & & & 0.059 & \\
\hline & OR & $95 \% \mathrm{Cl}$ & OR & $95 \% \mathrm{Cl}$ & OR & $95 \% \mathrm{Cl}$ & OR & $95 \% \mathrm{Cl}$ & OR & $95 \% \mathrm{Cl}$ & OR & $95 \% \mathrm{Cl}$ & OR & $95 \% \mathrm{Cl}$ & OR & $95 \% \mathrm{Cl}$ & OR & $95 \% \mathrm{Cl}$ \\
\hline \multicolumn{19}{|l|}{ Sex } \\
\hline \multirow{2}{*}{\multicolumn{19}{|c|}{ 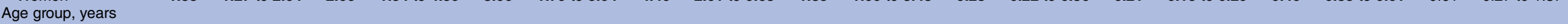 }} \\
\hline $70-79$ & & & & & & & & & & & & & & & & & & \\
\hline \multicolumn{19}{|c|}{0.84 to $1.36 \quad 1.10 \quad 0.82$ to $1.48 \quad 0.90 \quad 0.66$ to $1.23 \quad 1.20 \quad 0.62$ to 2.34} \\
\hline Central Germany & 1.05 & 0.74 to 1.50 & 1.35 & 0.80 to 2.28 & 0.95 & 0.57 to 1.59 & 1.35 & 0.67 to 2.71 & 1.06 & 0.54 to 2.09 & 1.47 & 1.10 to 1.98 & 1.19 & 0.82 to 1.72 & 0.78 & 0.53 to 1.13 & 1.60 & 0.59 to 4.35 \\
\hline Southern Germany & 1.09 & 0.72 to 1.64 & 1.14 & 0.66 to 1.98 & 1.33 & 0.75 to 2.36 & 1.31 & 0.61 to 2.83 & 1.09 & 0.49 to 2.45 & 2.35 & 1.72 to 3.22 & 1.95 & 1.34 to 2.86 & 1.45 & 0.96 to 2.21 & 1.46 & 0.51 to 4.19 \\
\hline \multicolumn{19}{|c|}{ (10 } \\
\hline Lower & 1.22 & 0.77 to 1.94 & 0.38 & 0.19 to 0.76 & 0.88 & 0.44 to 1.74 & 0.59 & 0.24 to 1.43 & 2.49 & 1.07 to 5.80 & 0.44 & 0.30 to 0.66 & 0.95 & 0.60 to 1.52 & 0.53 & 0.34 to 0.81 & 1.24 & 0.43 to 3.61 \\
\hline Middle & 1.08 & 0.76 to 1.55 & 0.72 & 0.45 to 1.15 & 1.01 & 0.58 to 1.75 & 0.68 & 0.33 to 1.39 & 1.29 & 0.58 to 2.84 & 0.73 & 0.52 to 1.03 & 1.00 & 0.73 to 1.37 & 0.65 & 0.46 to 0.92 & 1.26 & 0.54 to 2.96 \\
\hline \multicolumn{19}{|l|}{ Living alone } \\
\hline $\begin{array}{l}\text { Yes } \\
\text { Smoking }\end{array}$ & 1.11 & 0.80 to 1.55 & 1.15 & 0.65 to 2.02 & 1.57 & 1.02 to 2.43 & 0.64 & 0.33 to 1.25 & 0.91 & 0.49 to 1.71 & 0.71 & 0.52 to 0.98 & 0.65 & 0.44 to 0.98 & 0.86 & 0.61 to 1.22 & 1.21 & 0.54 to 2.69 \\
\hline Smoker & 1.05 & 0.67 to 1.65 & 1.03 & 0.46 to 2.29 & 1.00 & 0.59 to 1.69 & 1.74 & 0.71 to 4.27 & 1.84 & 0.81 to 4.18 & 1.16 & 0.78 to 1.73 & 2.60 & 1.69 to 4.00 & 2.41 & 1.52 to 3.82 & 1.44 & 0.55 to 3.78 \\
\hline \multirow{2}{*}{\multicolumn{19}{|c|}{ 烈 }} \\
\hline & & & & & & & & & & & & & & & & & & \\
\hline $\begin{array}{l}\text { Worse } \\
\text { Certified disability }\end{array}$ & 1.74 & 1.28 to 2.36 & 1.09 & 0.71 to 1.66 & 1.39 & 0.85 to 2.29 & 1.26 & 0.74 to 2.14 & 3.59 & 1.64 to 7.85 & 0.76 & 0.58 to 0.98 & 0.74 & 0.53 to 1.03 & 0.73 & 0.54 to 0.99 & 1.88 & 1.03 to 3.43 \\
\hline 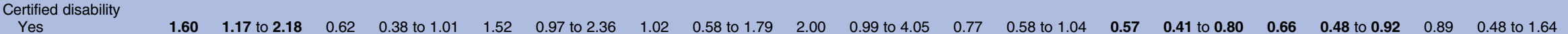 & 1.60 & 1.17 to 2.18 & 0.62 & 0.38 to 1.01 & 1.52 & 0.97 to 2.36 & 1.02 & 0.58 to 1.79 & 2.00 & 0.99 to 4.05 & 0.77 & 0.58 to 1.04 & 0.57 & 0.41 to 0.80 & 0.66 & 0.48 to 0.92 & 0.89 & 0.48 to 1.64 \\
\hline $\begin{array}{l}\text { Polypharmacy } \\
\text { Yes }\end{array}$ & 4.30 & 3.11 to 5.94 & 2.82 & 1.69 to 4.70 & 5.39 & 3.03 to 9.57 & 4.08 & 2.20 to 7.59 & 5.94 & 2.34 to 15.0 & 0.91 & 0.71 to 1.16 & 1.31 & 0.96 to 1.80 & 1.03 & 0.78 to 1.36 & 2.46 & 1.10 to 5.48 \\
\hline $\begin{array}{l}\text { ORs and } 95 \% \text { C } \\
2010 \text {. Figures in } \\
\text { certified disability } \\
\text { "Regions: Northe } \\
\text { Rhine-Westphali } \\
\text { †Polypharmacy: }\end{array}$ & re $\mathrm{d}$ & d from & istic & erlin, $\mathrm{Br}$ & dels & Breme & a & dep & 3a & $\begin{array}{l}\text { ecklenbur } \\
\text { a, Rhinela }\end{array}$ & $-P$ & nate, Saa & to & Ger & tione & $\begin{array}{l}\text { opulatio } \\
\text { orse he }\end{array}$ & $\begin{array}{l}31 \\
\text { sta }\end{array}$ & $\begin{array}{l}\text { cember } \\
\text { having no }\end{array}$ \\
\hline
\end{tabular}


risky drinking ${ }^{19}$ vary widely between countries and studies. ${ }^{32}$ For example, in the USA, drinking limits are two standard drinks or $28 \mathrm{~g}$ of alcohol per day for men and one standard drink or $14 \mathrm{~g}$ of alcohol for women, while in Germany, the threshold for risky drinking is set at $\geq 20-24 \mathrm{~g}$ /day for men and $\geq 10-12 \mathrm{~g} /$ day of alcohol for women. ${ }^{20} 2132$ In the USA, the National Health and Nutrition Examination Survey 2005-2008 finds that $53.6 \%$ of people 65 years and older are non-drinkers and $8.3 \%$ consume alcohol daily or almost daily in the past 12 months. ${ }^{36}$ In this study, $14.5 \%$ of the older alcohol consumers drink alcohol in excess of limits recommended by the National Institute on Alcohol Abuse and Alcoholism (NIAAA), namely drinking no more than three drinks a day and no more than seven drinks in a week. ${ }^{36}$ An analysis of the 2005 and 2006 National Survey on Drug Use and Health (NSDUH) assessing past-month alcohol use finds that among people aged 65 years and older, $13 \%$ of men and $8 \%$ of women report at-risk alcohol use (defined as two or more drinks on a usual drinking day within the past 30 days) and more than $14 \%$ of men and $3 \%$ of women report binge drinking (defined as five or more drinks on the same occasion on at least 1 day in the past 30 days). ${ }^{37}$ The NSDUH 2010 finds that $7.6 \%$ of people aged 65 years and older practice binge- and $1.6 \%$ heavy drinking (defined as five or more drinks on the same occasion on each of 5 or more days in the past 30 days) ${ }^{38}$ In Australia, $~ 18 \%$ of men and $4 \%$ of women aged 65-74 years are heavy drinkers ( $>14$ drinks/ week). ${ }^{39}$ In the UK, $27 \%$ of men and $14 \%$ of women aged 65 years and older are excessive drinkers (drinking on 5 or more days last week). ${ }^{40}$ Similar to our findings, in a Belgian study, about one in five older adults $(20.5 \%)$ practices heavy drinking ( $>8$ glasses/week) ${ }^{33}$ In an Irish study $19.7 \%^{10}$ and in a Spanish study $7.8 \%^{35}$ of older adults consume alcohol riskily. The former study defined risky drinking according to NIAAA recommendation, ${ }^{10}$ while the latter defined risky drinking as $\geq 40 \mathrm{~g}$ alcohol per day for men and $\geq 24 \mathrm{~g}$ alcohol per day for women, ${ }^{35}$ much higher than the thresholds used in our study. The thresholds used in our study are lower than those in some other studies, which may partly account for the prevalence differences between studies.

The American Geriatrics Society suggests that benzodiazepines or other sedative-hypnotics should not be used in older adults as first choice for insomnia, agitation or delirium because of the substantial risks associated with them. ${ }^{41}$ Concomitant use of alcohol and psychotropic drugs, particularly sedatives, hypnotics and benzodiazepines, may produce additional sedation and increase greatly the risk of injuries caused by falling and other accidents among older adults. ${ }^{5}$ Although 'concurrent' or 'concomitant' use of psychotropic drugs and alcohol has been investigated in previous studies, ${ }^{2} 9121442$ due to differences in observational windows for drug use and alcohol exposure, it actually cannot be guaranteed that participants were exposed to the two substances at the same time in these studies. $^{2} 9121442$ In the present study, we investigate daily alcohol drinking among psychotropic drug users to increase the possibility of a simultaneous exposure of the two substances at the same day. Among those who used any psychotropic medicines, $\sim 13 \%$ drink daily with no substantial differences between subgroups of psychotropic drugs (table 4). As most of those daily drinkers consume alcohol also riskily, this poses a great risk of interactions. Consistent with our findings, $18.0 \%$ of older adults taking antidepressants, $14.8 \%$ taking opioids, $13.0 \%$ taking antiepileptics, antipsychotics or hypnotics are found to be heavy drinkers in a large population-based study in Ireland. ${ }^{10}$ In a national representative sample of adults aged 60 years and older in Spain, $36.5 \%$ of sleeping pill users are moderate and $5.6 \%$ heavy alcohol drinkers. ${ }^{35}$ In our study, $62.4 \%$ of hypnotic and sedative users consume alcohol moderately and $18.7 \%$ riskily. Again, definition of risky drinking may explain some of the differences.

We identified certain groups with an increased risk of exposure to psychotropic substance use. Those who already belong to a vulnerable group (eg, worse health status, disability, polypharmacy) or women are also more frequently exposed to psychotropic drug use. European studies confirm these findings. ${ }^{27}{ }^{43}$ Male sex, people with an upper SES, those living with a partner, smokers and those with a better health status are more frequently daily alcohol consumers. These factors are consistent with studies on alcohol use in the USA ${ }^{44}$ Belgian, ${ }^{33}$ Ireland $^{10}$ and Finland. ${ }^{45}$ In particular, we find that people with a worse health status and polypharmacy are more likely to use a combination of the two substances. Generally, we assume that polypharmacy defined by the number of prescription drugs is related to health status based on the fact that polypharmacy is closely associated with multimorbidities (and thus probably poor health status). Yet, polypharmacy defined by the number of any drugs used may be related to the style of coping with health issues. However, sensitivity analyses suggest there is no substantial difference between the two different definitions of polypharmacy in our study. Health professionals should pay attention when prescribing psychotropic drugs to these vulnerable people.

Strengths of our study include the large sample size and using nationally representative data and standardised valid data collection tools. The weighted results allow generalisation to the community-dwelling older adults in Germany. Recall bias concerning medicine use is minimised by reducing the observation period to the last 7 days before the interview and by asking people to bring the packages of medication to the examination sites. However, there are some limitations to our study. First, we cannot exclude selection bias, as persons who are hospitalised or institutionalised were not included. Older community-dwelling people with cognitive impairment, depression or other mental or physical severe illness are likely to be under-represented in the national 
survey due to the need to travel to survey sites. Therefore, estimation of psychotropic drug use may be underestimated. A further weakness of our study is the age limit of 79 years. Older people usually consume more psychotropic medication. ${ }^{46}$ Additionally, underreporting of alcohol use is likely because people tend to answer questions concerning these substances according to social desirability. ${ }^{48}$

\section{CONCLUSION}

In summary, the use of psychotropic drugs and alcohol is common among older adults in Germany. Despite the high risk of synergetic effects of psychotropic drugs and alcohol, more than half of those who use any psychotropic drugs consume alcohol moderately or at least once a week, while about 13-14\% consumes alcohol daily or riskily. Health professionals should pay attention to particularly vulnerable people, such as those exposed to polypharmacy and people with a worse health status. Further investigations are needed to monitor trends in the use of specific subgroups of psychotropic medicines and to evaluate health effects in association with alcohol consumption patterns among older adults over time.

Acknowledgements The authors thank the survey participants for contributing towards our understanding of psychotropic substance use among older adults.

Contributors YD helped conceptualise the study, conducted the statistical analyses, interpreted the results, contributed to literature review and wrote the manuscript. I-KW helped conceptualise the study, provided the literature review, assisted in interpreting results and writing the manuscript. HK generated the original idea, coordinated, conceptualised and conducted the project, provided specific knowledge and reviewed the manuscript. HK is the guarantor who takes the responsibility for the study. All authors read and approved the final manuscript.

Funding This work was supported by the Federal Ministry of Health and the Robert Koch Institute. The German Health Interview and Examination Survey for Adults 2008-2011 was funded by the Federal Ministry of Health.

Competing interests None declared.

Ethics approval the Charité-Universitätsmedizin Berlin ethics committee.

Provenance and peer review Not commissioned; externally peer reviewed.

Data sharing statement No additional data are available.

Open Access This is an Open Access article distributed in accordance with the Creative Commons Attribution Non Commercial (CC BY-NC 4.0) license, which permits others to distribute, remix, adapt, build upon this work noncommercially, and license their derivative works on different terms, provided the original work is properly cited and the use is non-commercial. See: http:// creativecommons.org/licenses/by-nc/4.0/

\section{REFERENCES}

1. Havemann-Reinecke U, Weyerer S, Fleischmann $\mathrm{H}$, eds. Alkohol und Medikamente, Mißbrauch und Abhängigkeit im Alter. [Alcohol and medicine, abuse and dependency in older age]. Freiburg i. Breisgau: Lambertus Verlag, 1998.

2. llomäki J, Paljärvi T, Korhonen MJ, et al. Prevalence of concomitant use of alcohol and sedative-hypnotic drugs in middle and older aged persons: a systematic review. Ann Pharmacother 2013;47:257-68.

3. Trifiró G, Spina E. Age-related changes in pharmacodynamics: focus on drugs acting on central nervous and cardiovascular systems. Curr Drug Metab 2011;12:611-20.
4. Hammond T, Wilson A. Polypharmacy and falls in the elderly: a literature review. Nurs Midwifery Stud 2013;2:171-5.

5. Weathermon R, Crabb DW. Alcohol and medication interactions. Alcohol Res Health 1999;23:40-54.

6. Moore AA, Whiteman EJ, Ward KT. Risks of combined alcohol/ medication use in older adults. Am J Geriatr Pharmacother 2007:5:64-74

7. Hill KD, Wee R. Psychotropic drug-induced falls in older people: a review of interventions aimed at reducing the problem. Drugs Aging 2012;29:15-30.

8. Wang YP, Andrade LH. Epidemiology of alcohol and drug use in the elderly. Curr Opin Psychiatry 2013;26:343-8.

9. Breslow RA, Dong C, White A. Prevalence of alcohol-interactive prescription medication use among current drinkers: United States, 1999 to 2010. Alcohol Clin Exp Res 2015;39: 371-9.

10. Cousins G, Galvin R, Flood M, et al. Potential for alcohol and drug interactions in older adults: evidence from the Irish longitudinal study on ageing. BMC Geriatr 2014;14:57.

11. Immonen S, Valvanne J, Pitkälä KH. The prevalence of potential alcohol-drug interactions in older adults. Scand J Prim Health Care 2013;31:73-8.

12. Ilomäki J, Gnjidic D, Hilmer SN, et al. Psychotropic drug use and alcohol drinking in community-dwelling older Australian men: the CHAMP study. Drug Alcohol Rev 2013;32:218-22.

13. Ilomäki J, Korhonen $\mathrm{MJ}$, Enlund $\mathrm{H}$, et al. Risk drinking behavior among psychotropic drug users in an aging Finnish population: the FinDrink study. Alcohol 2008;42:261-7.

14. Du Y, Scheidt-Nave C, Knopf H. Use of psychotropic drugs and alcohol among non-institutionalised elderly adults in Germany. Pharmacopsychiatry 2008;41:242-51.

15. Scheidt-Nave C, Kamtsiuris P, Gößwald A, et al. German health interview and examination survey for adults (DEGS)—design, objectives and implementation of the first data collection wave. BMC Public Health 2012;12:730.

16. Kamtsiuris $\mathrm{P}$, Lange $\mathrm{M}$, Hoffmann $\mathrm{R}$, et al. [The first wave of the German Health Interview and Examination Survey for Adults (DEGS1): sample design, response, weighting and representativeness]. Bundesgesundheitsblatt Gesundheitsforschung Gesundheitsschutz 2013;56:620-30.

17. Knopf H, Grams D. [Medication use of adults in Germany: results of the German Health Interview and Examination Survey for Adults (DEGS1)]. Bundesgesundheitsblatt Gesundheitsforschung Gesundheitsschutz 2013;56:868-77.

18. Burger M, Mensink G, Brönstrup A, et al. Alcohol consumption and its relation to cardiovascular risk factors in Germany. Eur $J$ Clin Nutr 2004;58:605-14.

19. Dawson DA. Defining risk drinking. Alcohol Res Health 2011;34:144-56.

20. Burger M, Mensink GB. High alcohol consumption in Germany: results of the German National Health Interview and Examination Survey 1998. Public Health Nutr 2004;7:879-84.

21. Bundeszentrale für gesundheitliche Aufklärung (BZgA) (Hrsgb.) Alkohol. Kenn dein Limit. (Alcohol. Know your limit). http://www. kenn-dein-limit.de/alkohol/riskanter-konsum/ (accessed 9 Sep 2015)

22. Lampert T, Kroll LE, Müters $\mathrm{S}$, et al. [Measurement of the socioeconomic status within the German Health Update 2009 (GEDA)]. Bundesgesundheitsblatt Gesundheitsforschung Gesundheitsschutz 2013;56:131-43.

23. John U, Baumeister SE, Völzke H, et al. Sedative, hypnotic, anxiolytic and opioid medicament use and its co-occurrence with tobacco smoking and alcohol risk drinking in a community sample. BMC Public Health 2007;7:337.

24. Frenk SM, Porter KS, Paulozzi LJ. Prescription opioid analgesic use among adults: United States, 1999-2012. NCHS Data Brief 2015;189:1-8.

25. Harris MG, Burgess PM, Pirkis J, et al. Correlates of antidepressant and anxiolytic, hypnotic or sedative medication use in an Australian community sample. Aust N Z J Psychiatry 2011;45:249-60.

26. Lewer D, O'Reilly C, Mojtabai R, et al. Antidepressant use in 27 European countries: associations with sociodemographic, cultural and economic factors. Br J Psychiatry 2015;207:221-6.

27. Boyd A, Van de Velde S, Pivette M, et al. Gender differences in psychotropic use across Europe: results from a large cross-sectional, population-based study. Eur Psychiatry 2015;30:778-88.

28. Abbing-Karahagopian V, Huerta C, Souverein PC, et al Antidepressant prescribing in five European countries: application of common definitions to assess the prevalence, clinical observations, and methodological implications. Eur J Clin Pharmacol 2014;70:849-57. 
29. Demyttenaere K, Bonnewyn A, Bruffaerts R, et al. Clinical factors influencing the prescription of antidepressants and benzodiazepines: results from the European study of the epidemiology of mental disorders (ESEMeD). J Affect Disord 2008;110:84-93.

30. Alonso J, Angermeyer MC, Bernert S, et al. Psychotropic drug utilization in Europe: results from the European Study of the Epidemiology of Mental Disorders (ESEMeD) project. Acta Psychiatr Scand 2004;109 (Suppl 420):55-64.

31. Rehm J, Anderson P, Barry J, et al. Prevalence of and potential influencing factors for alcohol dependence in Europe. Eur Addict Research 2015;21:6-18.

32. Gell L, Meier PS, Goyder E. Alcohol consumption among the over 50s: international comparisons. Alcohol Alcohol (Oxford, Oxfordshire) 2015;50:1-10.

33. Hoeck S, Van Hal G. Unhealthy drinking in the Belgian elderly population: prevalence and associated characteristics. Eur J Public Health 2013;23:1069-75.

34. Substance Abuse and Mental Health Services Administration. Results from the 2010 National Survey on Drug Use and Health: Summary of National Findings, NSDUH Series H-41, HHS Publication No. (SMA) 11-4658. Rockville, MD: Substance Abuse and Mental Health Services Administration, 2011.

35. León-Muñoz LM, Galán I, Donado-Campos J, et al. Patterns of alcohol consumption in the older population of Spain, 2008-2010. $J$ Acad Nutr Diet 2015;115:213-24.

36. Wilson SR, Knowles SB, Huang Q, et al. The prevalence of harmfu and hazardous alcohol consumption in older U.S. adults: data from the 2005-2008 National Health and Nutrition Examination Survey (NHANES). J Gen Intern Med 2014;29:312-19.

37. Blazer DG, Wu LT. The epidemiology of at-risk and binge drinking among middle-aged and elderly community adults: National Survey on Drug Use and Health. Am J Psychiatry 2009;166:1162-9.

38. Substance Abuse and Mental Health Services Administration. Results from the 2010 National Survey on Drug Use and Health Summary of National Findings, NSDUH Series H-41, HHS Publication No. (SMA) 11-4658. Rockville, MD: Substance Abuse and Mental Health Services Administration, 2011. http://www. samhsa.gov/data/sites/default/files/
NSDUHNationalFindingsResults2010-web/2k10ResultsRev/ NSDUHresultsRev2010.pdf (accessed 12 Apr 2015).

39. French DJ, Sargent-Cox KA, Kim S, et al. Gender differences in alcohol consumption among middle-aged and older adults in Australia, the United States and Korea. Aust N Z J Public Health 2014;38:332-9.

40. Robinson S, Harris H. Smoking and drinking among adults, 2009. A report on the 2009 General Lifestyle Survey. Office for National Statistics, 2011.

41. American Geriatrics Society. Don't use benzodiazepines or other sedative-hypnotics in older adults as first choice for insomnia, agitation or delirium. http://www.choosingwisely.org/clinician-lists/ american-geriatrics-society-benzodiazepines-sedative-hypnotics-forinsomnia-in-older-adults/ (accessed 5 Aug 2016)

42. Pringle KE, Ahern FM, Heller DA, et al. Potential for alcohol and prescription drug interactions in older people. J Am Geriatr Soc 2005;53:1930-6.

43. Carrasco-Garrido $\mathrm{P}$, López de Andrés $\mathrm{A}$, Barrera $\mathrm{VH}$, et al. National trends (2003-2009) and factors related to psychotropic medication use in community-dwelling elderly population. Int Psychogeriatr 2013:25:328-38.

44. Platt A, Sloan FA, Costanzo P. Alcohol-consumption trajectories and associated characteristics among adults older than age 50. J Stud Alcohol Drugs 2010;71:169-79.

45. Immonen S, Valvanne J, Pitkala K. Prevalence of at-risk drinking among older adults and associated sociodemographic and health-related factors. J Nutr Health Aging 2011;15: 789-94.

46. Linden M, Bar T, Helmchen H. Prevalence and appropriateness of psychotropic drug use in old age: results from the Berlin Aging Study (BASE). Int Psychogeriatr 2004;16:461-80.

47. Sonntag A, Matschinger $\mathrm{H}$, Angermeyer MC, et al. Does the context matter? Utilization of sedative drugs in nursing homes-a multilevel analysis. Pharmacopsychiatry 2006;39:142-9.

48. Stockwell T, Zhao J, Greenfield T, et al. Estimating under- and over-reporting of drinking in national surveys of alcohol consumption: Identification of consistent biases across four English-speaking countries. Addiction 2016;111:1203-13. 